\title{
Relação Entre Tempo e Besouros em Mata de Cocal
}

\author{
Marcos Paulo Gomes Gonçalves ${ }^{1}$ \\ ${ }^{1}$ Centro de Ciências Agrárias, Universidade Federal do Piauí, Teresina, PI, Brasil.
}

Recebido em 5 de Setembro de 2015 - Aceito em 24 de Agosto de 2017/

\begin{abstract}
Resumo
O estudo dos fatores temporais na flutuação populacional dos besouros é de fundamental importância para a compreensão da variação que ocorre em sua população. Assim, analisou-se relação entre tempo e flutuação populacional de coleópteros em Mata de Cocal no município de Teresina-PI no período de agosto de 2011 a julho de 2012. Coletaram-se besouros semanalmente em 12 armadilhas pitfall sem atrativos. Confirma-se correlação canônica entre o conjunto de registro de ocorrência mensal da flutuação populacional das famílias Scarabaeidae, Carabidae, Tenebrionidae, Curculionidae, Bolboceratidae, Histeridae e Chrysomelidae e o conjunto de dados mensais de insolação, de precipitação pluviométrica, da umidade relativa do ar e da temperatura média, com magnitude de 0,99, Qui-Quadrado igual a 66,62 , com 28 graus de liberdade e o correspondente p-valor igual a $<0,0001$. Significativamente $(\mathrm{p}<0,0001)$, houve correlação canônica positiva entre os dados da insolação $(0,81)$ e da precipitação pluviométrica $(0,45)$, e negativa da umidade $(-0,75)$ e da temperatura $(-0,21)$ ao conjunto dos registros de ocorrência mensal da flutuação populacional de famílias de coleópteros. Deste modo, a flutuação populacional da comunidade de besouros é regida predominantemente pelas variáveis temporais da região em que se encontram e que a sua presença é estacional e condicionada por parâmetros meteorológicos, principalmente insolação e umidade relativa do ar.
\end{abstract}

Palavras-chave: biometeorologia, entomologia, ecologia.

\section{Relationship Between Meteorological Conditions and Beetles in Mata de Cocal}

\begin{abstract}
Study the meteorological factors is important to understand beetles population dynamics. So this study examined the relationship between meteorological conditions and the Coleptera population fluctuation in Mata de Cocal in Teresina-PI city from August 2011 to July 2012. Insects were collected weekly in 12 pitfall traps unattractive. It is confirmed canonical correlation between the monthly occurrence record in the families population fluctuation-Scarabaeidae, Carabidae, Tenebrionidae, Curculionidae, Bolboceratidae, Histeridae and Chrysomelidae - in the group of monthly data of insolation, pluviometric precipitation, relative humidity and temperature, with a magnitude of 0.99 , chi-square equal to 66.62 with 28 degrees of freedom and $p$-value corresponding equal to $<0.0001$. Significantly $(p<0.0001)$ there was positive canonical correlation between insolation data $(0.81)$ and pluviometric precipitation $(0.45)$, and negative for humidity $(-0.75)$ and temperature $(-0.21)$ in the monthly occurrence record of the group these families. In this way the population fluctuation and governed predominantly by regional variables and their presence is conditioned by meteorological parameters, principally insolation and humidity.
\end{abstract}

Keywords: biometeorology, entomology, ecology.

\section{Introdução}

Dentre os insetos, a ordem Coleoptera Linnaeus, 1758, é a maior dentre todas da classe Insecta, possui cerca de 350.000 espécies conhecidas, representando quase metade das espécies de insetos descritas (Triplehorn e Johnson, 2005). Os coleópteros, conhecidos popularmente como besouros, são indicadores importantes da qualidade do meio ambiente, devido à ocorrência em quantidade e diversidade de habitats que ocupam. Como explicam Doyen et al. (1998), o sucesso desta ordem é atribuído principalmente à presença de élitros e aos diversos hábitos alimentares que suas espécies possuem.

Autor de correspondência: Marcos Paulo Gomes Gonçalves, mpgg1988@gmail.com. 
Conforme Lima (1952a), os élitros são asas mesotorácicas, completamente diferenciados em bainhas de consistência coriácea ou córnea, que protegem as asas membranáceas, metatorácicas. A forte esclerose dos élitros e do exosqueleto possibilitam facilmente distinguir os besouros dos demais insetos. De acordo com os hábitos alimentares, Marinoni (2001) categoriza os coleópteros em cinco grupos tróficos: (i) Carnívoros; (ii) Detritívoros; (iii) Fungívoros; (iv) Herbívoros; e (v) Algívoros. Gallo et al. (2002) afirmam que apenas não registrou-se a hematofagia, hábito de se alimentar com sangue, para essa ordem.

Costa et al. (2014) consideram que os besouros constituem-se em importantes organismos do ponto de vista econômico e ecológico, por apresentar representantes que podem ser pragas (florestais e agrícolas), inimigos naturais (predadores), decompositores de matéria orgânica e ainda polinizadores, o que torna a ordem alvo de trabalhos de levantamento. Costa (1999) relata a ocorrência de besouros no solo, nas plantas, nas águas de rios, nos riachos e nas praias marinhas. Marinoni e Ganho (2003) e Paiva (2009) observaram associação dos coleópteros aos fatores bióticos - relação com os vegetais - e aos fatores abióticos - como a sazonalidade com suas características de temperatura, umidade do ar, pluviosidade e fotoperíodo; além das condições edáficas do solo; dentre outros fatores.

Em área de cana-de-açúcar com fragmentos de vegetação de Mata de Cocal, Branco (2008) obteve grande número e diversidade de insetos da ordem Coleóptera, identificou 22 famílias, cujos insetos predominantes coletados encontram-se distribuídos nas famílias Hydrophilidae, Scarabaeidae, Gyrinidae, Carabidae, Metasidae, Buprestidae e Platypodidae. Ao estudar a relação da família Scarabaeidae aos dados meteorológicos de área de capim andropogon com fragmento de Mata de Cocal, Paiva (2009) obteve que a flutuação populacional das espécies desta família de besouros é estacional e condicionada por variáveis meteorológicas, principalmente precipitação pluviométrica e umidade relativa do ar.

Os besouros como todos os seres vivos estão sujeitos as forças da natureza, assim, pode haver influência que pode inibir ou favorecer o desenvolvimento de determinada família. Destarte, o estudo dos fatores temporais na flutuação populacional dos besouros é de fundamental importância para a compreensão da variação que ocorre em sua população.

Por ser um assunto relevante e para complementar a literatura científica acerca dessa ordem de insetos quando associados à Mata de Cocal e às variáveis meteorológicas, $\mathrm{o}$ presente trabalho objetivou analisar a relação da temperatura média do ar compensada, da umidade relativa do ar compensada, da precipitação pluviométrica e da insolação na flutuação populacional de coleópteros em Mata de Cocal.

\section{Metodologia}

Realizou-se este estudo no Centro de Ciências Agrárias - CCA, no Campus Agrícola do Socopo da Universidade Federal do Piauí -UFPI, na região de Teresina-PI, no período de agosto de 2011 a julho de 2012. Andrade Júnior et al. (2005) descrevem o clima do município de Teresina de acordo com a classificação de Thornthwaite e Mather (1955) como sendo C1sA'a', caracterizado como subúmido seco, megatérmico, com excedente hídrico moderado no verão e uma concentração de $32,2 \%$ da evapotranspiração potencial no trimestre - setembro, outubro e novembro.

Utilizou-se para a amostragem uma área de vegetação nativa, latitude e longitude respectivas de $5^{\circ} 2^{\prime} 52^{\prime \prime} \mathrm{S}$ e $42^{\circ} 47^{\prime} 11^{\prime \prime} \mathrm{O}$, que apresenta formação vegetal típica de Mata de Cocal, que de acordo com Branco (2008) se caracteriza por ser uma área de transição entre floresta Amazônica e Cerrado, com predomínio da palmeira coco babaçu (Orbignya martiana). Geograficamente esta grande transição concentra-se sobre os estados do Piauí e do Maranhão, porção mais oeste da região Nordeste, amplamente ocupada por formações dicótilo-palmácea, segundo IBGE (1992). Em termos vegetacionais, forma-se um extenso mosaico com fisionomias tão díspares que se observa em pouco espaço a especialidade da região em ter disseminadas feições com diferentes espécies e estruturas, acompanhadas por variações nos solos e no clima (Santos-Filho et al., 2010). Conforme Farias e Castro (2004), o meio norte do Brasil - Piauí e Maranhão - apresenta-se como uma extensa zona ecotonal situada entre o subúmido amazônico e o semiárido nordestino. O solo da área amostrada, de acordo com o Sistema Brasileiro de Classificação de Solos - EMBRAPA (2006) -, é Argissolo Vermelho-Amarelo, Distrófico, com textura arenosa média, muito profundo, ácido e com relevo plano.

Para as amostras, utilizou-se de armadilhas de solo, pitfall, sem atrativos, as quais Paiva (2009) e Costa et al. (2014) utilizaram e com as quais se empregam na captura de animais de solo. Obtiveram-se as amostras em unidades amostrais independentes, chamadas de "estações" localizadas no chão. Cada estação consistiu de quatro recipientes de plástico, cada um com capacidade de $500 \mathrm{~mL}$, diâmetro de $10 \mathrm{~cm}$ e altura de $11 \mathrm{~cm}$, os quais receberam uma cobertura de um prato plástico de $20 \mathrm{~cm}$ de diâmetro, suspenso por peças de madeira com aproximadamente $15 \mathrm{~cm}$, para impedir ou diminuir a entrada de água no período das chuvas. Enterraram-se os recipientes com a borda ao nível do solo e em cada um adicionou-se $200 \mathrm{~mL}$ de solução formol $4 \%$ como líquido fixador. Interligaram-se os frascos por anteparos de metal com $100 \mathrm{~cm}$ de comprimento por $20 \mathrm{~cm}$ de altura, com função de guiar os insetos até um dos recipientes da estação, dispostas no formato de um Y. Por meio da Fig. 1 (adaptada), observa-se desenho esquemático da estação utilizada para a coleta de insetos de solo.

Havia na área amostrada três estações iguais, dispostas aleatoriamente. Cada estação guardava entre si distância 


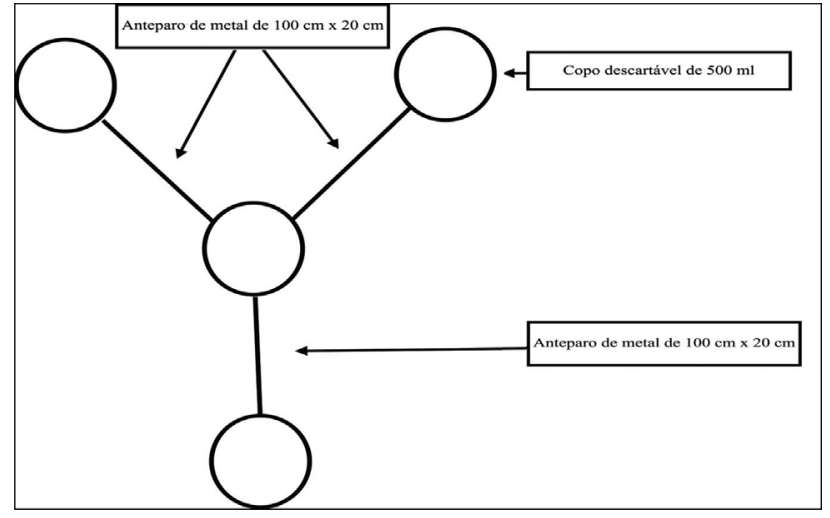

Figura 1 - Desenho esquemático de uma estação para coleta de insetos de solo, pitfall, adaptado.

de cerca de $5 \mathrm{~m}$. Obtiveram-se amostras semanais, o que totalizaram 52 amostras no período de agosto de 2011 a julho de 2012. Pôs-se o material em frascos coletores, e transferiu-se para recipientes devidamente identificados, posteriormente, no laboratório de Fitossanidade do Departamento de Fitotecnia do CCA da UFPI, triaram-se e identificaram-se os espécimes da ordem Coleoptera até o nível de família. Depositou-se o material amostrado na coleção entomológica do referido laboratório, de forma a preservar as informações, e assim, estarem disponíveis para estudos futuros.

Obtiveram-se os dados meteorológicos mensais da temperatura média do ar compensada, da umidade relativa do ar compensada, da precipitação pluviométrica e da insolação através da rede do Instituto Nacional de Meteorologia - INMET. A estação meteorológica do INMET da qual são originários os dados meteorológicos obtidos possui latitude e longitude respectivas de $5^{\circ} 2^{\prime} 5^{\prime}$ " S e $42^{\circ} 48^{\prime} 5^{\prime}$ ' O e altitude de $75 \mathrm{~m}$. A área de mata nativa, em qual obtiveram-se as amostras, está dentro de um raio de $3 \mathrm{~km}$ da referida estação meteorológica.

Utilizou-se para o cálculo da similaridade para comparação entre as famílias identificadas de coleópteros do presente estudo com as das de outros trabalhos o índice de similaridade de Sorensen descrito por Brower e Zar (1984), que consiste na multiplicação por 2 do número de famílias em comum nos dois trabalhos em comparação e posterior divisão pelo somatório do número de famílias identificadas dos respectivos estudos. O resultado multiplica-se por 100 para expressão em percentagem.

Calculou-se a partir dos dados obtidos correlação pelo método de Pearson entre o registro de ocorrência mensal da flutuação populacional de famílias de coleópteros e os dados mensais das variáveis meteorológicas através do software BIOESTAT versão 5.3 (Ayres, 2007). Posteriormente, realizou-se pelo mesmo software correlação canônica entre o conjunto de ocorrência mensal da flutuação populacional das famílias que apresentaram associação significativa, $\mathrm{p}<0,10$, em, pelo menos, a uma das variáveis meteorológicas estudadas e o conjunto dos dados mensais meteorológicos citados.

\section{Resultados e Discussão}

\subsection{Flutuação populacional}

Observa-se pela Tabela 1 que no período analisado na Mata de Cocal, amostraram-se 2.123 insetos da ordem coleóptera, identificados em 16 famílias - Scarabaeidae, Carabidae, Tenebrionidae, Curculionidae, Bolboceratidae, Histeridae, Chrysomelidae, Scolytidae, Stafilinidae, Nitidulidae, Elateridae, Meloidae, Mordellidae, Bruchidae, Cantharidae e Cerambycidae. Destacaram-se as famílias Scarabaeidae, Scolytidae, Carabidae e Tenebrionidae, com 1.120; 569; 224 e 87 espécimes, respectivamente. O mesmo que 52,76; 26,80; 10,55 e $4,10 \%$ do total de besouros amostrados, respectivamente. As outras 12 famílias restantes, quando juntas, apresentaram 123 indivíduos, os quais representaram $5,79 \%$ do total de coleópteros registrados.

A flutuação populacional de besouros variou do mínimo de 6 espécimes, outubro de 2011, ao máximo de 649 coleópteros, abril de 2012, que representam algo em torno de $0,3 \%$ no mínimo e $30,6 \%$ no máximo da população total dos coleópteros amostrados durante o já referido período. De dezembro de 2011 a maio de 2012, amostraram-se 1.844 coleópteros, cerca de $86,9 \%$ do total de besouros identificados, enquanto nos meses de agosto a novembro de 2011 e de junho a julho de 2012 identificaram-se 279 espécimes, cerca de $13,2 \%$ do total de coleópteros amostrados.

Para comparação da predominância, da diversidade e do número de famílias identificadas do presente trabalho com o de outras localidades da região Nordeste do Brasil é necessário que se citem estudos já desenvolvidos nessa região. Por exemplo:

Branco (2008) em área de cana-de-açúcar com fragmentos de vegetação de Mata de Cocal no município de União - PI por meio de armadilha luminosa, modelo "Luiz de Queiroz”, obteve 22 famílias de coleópteros, cujos insetos predominantes amostrados desta ordem encontraram-se distribuídos nas seguintes famílias: Hydrophilidae, Scarabaeidae, Gyrinidae, Carabidae, Metasidae, Buprestidae e Platypodidae; sendo que a família Scarabaeidae apresentou cerca de 78,3\% do total dos insetos desta ordem. Em fragmento de mata atlântica no Rio Grande do Norte, Lima et al. (2010) obtiveram por meio de armadilha de interceptação 28 famílias, onde se destacaram as famílias Elateridae, Coccinelidae, Chrysomelidae, Mordelidae e Curculionidae. Costa et al. (2014) avaliando a diversidade de coleópteros em área cultivada com melancia no semiárido do Rio Grande do Norte por meio da armadilha pitfall obtiveram 12 famílias cujas maiores abundâncias relativas foram de espécimes das famílias 
Tabela 1 - Registros de ocorrência mensal da flutuação populacional de famílias de coleópteros amostrados em área de Mata de Cocal no município de Teresina- PI de agosto de 2011 a julho de 2012.

\begin{tabular}{|c|c|c|c|c|c|c|c|c|c|c|c|c|c|}
\hline \multirow[t]{2}{*}{ Famílias } & \multicolumn{5}{|c|}{2011} & \multicolumn{7}{|c|}{2012} & \multirow[t]{2}{*}{ Total } \\
\hline & Ago. & Set. & Out. & Nov. & Dez. & Jan. & Fev. & Mar. & Abr. & Mai. & Jun. & Jul. & \\
\hline Scarabaeidae & 7 & 1 & 2 & 104 & 175 & 197 & 120 & 217 & 71 & 194 & 30 & 2 & 1120 \\
\hline Scolytidae & - & - & - & - & - & - & - & - & 506 & 45 & 18 & - & 569 \\
\hline Carabidae & 2 & 14 & & 3 & 2 & 26 & 67 & 52 & 44 & 9 & 5 & - & 224 \\
\hline Tenebrionidae & 20 & 26 & 4 & 2 & - & 1 & 5 & 1 & - & 1 & 3 & 24 & 87 \\
\hline Stafilinidae & - & - & - & - & - & - & - & - & 16 & 12 & 1 & - & 29 \\
\hline Curculionidae & - & 1 & - & - & 1 & 8 & 4 & - & 7 & - & 1 & - & 22 \\
\hline Nitidulidae & 1 & 1 & - & - & - & - & 4 & 3 & 2 & 9 & 1 & - & 21 \\
\hline Bolboceratidae & - & - & - & - & - & - & 12 & 1 & 2 & - & - & - & 15 \\
\hline Histeridae & - & - & - & - & - & 2 & - & 9 & - & - & - & - & 11 \\
\hline Chrysomelidae & - & - & - & 1 & - & 1 & 4 & 2 & 1 & - & 1 & - & 10 \\
\hline Elateridae & - & - & - & - & 4 & 3 & - & - & - & 2 & - & - & 9 \\
\hline Meloidae & - & - & - & - & 1 & - & - & - & - & - & 1 & - & 2 \\
\hline Mordellidae & - & - & - & - & - & - & - & - & - & - & 1 & - & 1 \\
\hline Bruchidae & 1 & - & - & - & - & - & - & - & - & - & - & - & 1 \\
\hline Cantharidae & - & - & - & 1 & - & - & - & - & - & - & - & - & 1 \\
\hline Cerambycidae & - & - & - & - & - & 1 & - & - & - & - & - & - & 1 \\
\hline Total & 31 & 43 & 6 & 111 & 183 & 239 & 216 & 285 & 649 & 272 & 62 & 26 & 2123 \\
\hline
\end{tabular}

Scarabaeidae (93,65\%), Staphylinidae $(1,94 \%)$ e Curculionidae (1,76\%).

Há similaridade de Sorensen de 57,9; 54,5 e 71,4\% entre o número de famílias identificadas de besouros do presente estudo e o número de famílias identificadas por Branco (2008), por Lima et al. (2010) e por Costa et al. (2014), respectivamente. Nesse e em todos esses trabalhos, houve o registro das famílias Scarabaeidae, Chrysomelidae, Scolytidae, Tenebrionidae, Curculionidae, Carabidae e Elateridae. A diferença da predominância, da diversidade e do número de famílias identificadas de coleópteros do presente estudo em comparação com o dos demais estudos citados pode ser explicada pela utilização de armadilhas diferentes e do número das mesmas e do número de amostras obtidas; além da relação dos insetos aos fatores bióticos- relação com os vegetais; competições intra e interespecíficas; diversidade de mamíferos, os quais possibilitam maior ou menor disponibilidade e diversidade de excrementos - e aos fatores abióticos - como a sazonalidade com suas características de temperatura, umidade do ar, pluviosidade e fotoperíodo; além das condições edáficas do solo; dentre outros fatores.

\subsection{Besouros e variáveis meteorológicas}

\subsubsection{Dados meteorológicos}

Ao longo do estudo, houve no município de Teresina média de insolação de $8,4 \mathrm{~h} \cdot \mathrm{d}^{-1}$, umidade relativa média do ar compensada de $72,4 \%$, temperatura média do ar compensada diária de $27,4{ }^{\circ} \mathrm{C}$ e $1.218,9 \mathrm{~mm}$ de precipitação pluviométrica, em comparação à normal climatológica de 1980 a 2009, calculada por Bastos e Andrade Júnior (2011), a qual teve como insolação média de $7,8 \mathrm{~h} \cdot \mathrm{d}^{-1}$, umidade relativa do ar de $69,8 \%$, temperatura média do ar de $28,2{ }^{\circ} \mathrm{C}$ e $1.351,9 \mathrm{~mm}$ de precipitação total anual. Consta na Tabela 2 o registro dos dados meteorológicos mensais do referido período.

\subsubsection{Relação entre besouros e variáveis meteorológicas}

Os besouros como todos os seres vivos estão sujeitos às forças da natureza, assim, há influência relevante de forma que pode inibir ou favorecer o desenvolvimento de determinada família. Destarte, o estudo dos fatores temporais na flutuação populacional dos besouros é de fundamental importância para a compreensão da variação que ocorre em sua população.

Para averiguação e compreensão dessa associação em Mata de Cocal, correlacionaram-se os registros de ocorrência mensal da flutuação populacional de famílias de coleópteros e os dados mensais meteorológicos. Tiveram associação significativa, com $\mathrm{p}<0,10$ e 10 graus de liberdade, em, pelo menos, a uma das variáveis meteorológicas estudadas as famílias Scarabaeidae, Carabidae, Tenebrionidae, Curculionidae, Bolboceratidae, Histeridae $e$ Chrysomelidae como se observa pela Tabela 3. Seis famílias - Scarabaeidae, Carabidae, Tenebrionidae, Curculionidae, Bolboceratidae, e Chrysomelidae - associaram-se à insolação; quatro - Scarabaeidae, Carabidae, Tenebrionidae, e Chrysomelidae - associaram-se à umidade; quatro - Carabidae, Bolboceratidae, Histeridae e 
Tabela 2 - Dados meteorológicos (Insolação, Umidade relativa média ar compensada, Precipitação Pluviométrica e Temperatura média do ar compensada), de 01 de Agosto de 2011 a 31 de Julho de 2012, no município de Teresina- Piauí.

\begin{tabular}{|c|c|c|c|c|c|}
\hline Ano & Meses & Insolação $\left(h \cdot d^{-1}\right)$ & Umidade relativa média do ar (\%) & Precipitação (mm) & Temperatura média $\left({ }^{\circ} \mathrm{C}\right)$ \\
\hline \multirow[t]{5}{*}{2011} & Agosto & 10,1 & 65,4 & 10,8 & 27,2 \\
\hline & Setembro & 10,3 & 58,1 & 0,6 & 28,5 \\
\hline & Outubro & 8,8 & 66,1 & 167,6 & 28,6 \\
\hline & Novembro & 7,8 & 74,8 & 124,6 & 27,4 \\
\hline & Dezembro & 8,6 & 68,2 & 23,4 & 28,3 \\
\hline \multirow[t]{7}{*}{2012} & Janeiro & 6,4 & 75,7 & 133,1 & 27,1 \\
\hline & Fevereiro & 5,6 & 83,4 & 317,1 & 26,2 \\
\hline & Março & 7,4 & 85 & 264 & 26,3 \\
\hline & Abril & 7,7 & 82,5 & 121 & 26,7 \\
\hline & Maio & 9,3 & 77,3 & 31,3 & 27,2 \\
\hline & Junho & 8,8 & 72,7 & 25,4 & 27,2 \\
\hline & Julho & 10 & 60,8 & 0 & 27,5 \\
\hline
\end{tabular}

Fonte: Dados da Rede do INMET.

Tabela 3 - Correlação entre os registros de ocorrência mensal da flutuação populacional de famílias de coleópteros e dados mensais meteorológicos em área de Mata de Cocal no município de Teresina- PI de agosto de 2011 a julho de 2012.

\begin{tabular}{|c|c|c|c|c|c|c|c|c|}
\hline & \multicolumn{2}{|c|}{ Insolação } & \multicolumn{2}{|c|}{ Umidade } & \multicolumn{2}{|c|}{ Precipitação } & \multicolumn{2}{|c|}{ Temperatura } \\
\hline & (r) & p- valor & (r) & p- valor & (r) & $\mathrm{p}$ - valor & (r) & $\mathrm{p}$ - valor \\
\hline \multicolumn{9}{|l|}{ Famílias } \\
\hline Scarabaeidae & $-0,55$ & $<0,10$ & 0,68 & $<0,05$ & 0,41 & $\mathrm{~ns}$ & $-0,33$ & $\mathrm{~ns}$ \\
\hline Carabidae & $-0,70$ & $<0,05$ & 0,76 & $<0,01$ & $\mathbf{0 , 8 0}$ & $<0,01$ & $-0,78$ & $<0,01$ \\
\hline Tenebrionidae & 0,73 & $<0,01$ & $-0,78$ & $<0,01$ & $-0,48$ & $\mathrm{~ns}$ & 0,30 & $\mathrm{~ns}$ \\
\hline Curculionidae & $-0,60$ & $<0,05$ & 0,43 & $\mathrm{~ns}$ & 0,29 & $\mathrm{~ns}$ & $-0,38$ & $\mathrm{~ns}$ \\
\hline Bolboceratidae & $-0,61$ & $<0,05$ & 0,49 & $\mathrm{~ns}$ & 0,69 & $<0,05$ & $-0,55$ & $<0,10$ \\
\hline Histeridae & $-0,26$ & $\mathrm{~ns}$ & 0,45 & $\mathrm{~ns}$ & $\mathbf{0 , 5 0}$ & $<0,10$ & $-0,42$ & $\mathrm{~ns}$ \\
\hline Chrysomelidae & $-0,81$ & $<0,01$ & 0,72 & $<0,01$ & 0,85 & $<0,01$ & $-0,72$ & $<0,01$ \\
\hline
\end{tabular}

$\mathrm{N}=12, \mathrm{GL}=10$.

Chrysomelidae - associaram-se positivamente à precipitação pluviométrica; e três - Carabidae, Bolboceratidae e Chrysomelidae - associaram-se negativamente à temperatura. As famílias Scolytidae, Stafilinidae, Nitidulidae, Elateridae, Meloidae, Mordellidae, Bruchidae, Cantharidae e Cerambycidae, com p-valor igual a >0,10 não obtiveram associação significativa. Conforme as Figs. 2, 3, 4 e 5, nota-se que somente as famílias Carabidae e Chrysomelidae associaram-se significativamente a todas as variáveis meteorológicas. A família Tenebrionidae foi a única que apresentou associação negativa significativa à umidade e associação positiva significativa à insolação.

Realizou-se correlação canônica entre o registro de ocorrência mensal das famílias Scarabaeidae, Carabidae, Tenebrionidae, Curculionidae, Bolboceratidae, Histeridae e Chrysomelidae com o conjunto dos dados meteorológicos relativos à insolação, à umidade, à precipitação pluviométrica e à temperatura. Observa-se pelas Tabelas 4 e 5 as correlações canônicas e os autovalores. A correlação canô- nica entre o par de variáveis canônicas é 0,99 . Este valor, também denominado R Canônico, representa a melhor correlação possível entre qualquer combinação linear dos dados meteorológicos mensais com os registros de ocorrência mensal dos espécimes das famílias de coleópteros. A estatística R Canônica expressa a magnitude do relacionamento entre os dois conjuntos de variáveis. Confirma-se a associação entre os conjuntos de variáveis registro de ocorrência mensal da flutuação populacional de famílias de besouros e dados meteorológicos mensais, pelo Qui-Quadrado $\left(\chi^{2}\right)$ igual a 66,62, com 28 graus de liberdade e o correspondente p-valor igual a $<0,0001$, que é muito significativo.

Como os insetos são animais pecilotérmicos, não possuem sistema de termo regulação, a temperatura é um fator regulador da temperatura destes seres vivos. Rodrigues (2004) aponta que a temperatura age diretamente nos insetos reduzindo a taxa metabólica, interferindo no seu desenvolvimento - fase de ovo, larva e pupa - e no seu comportamento. Deste modo, Rodrigues (2004) considera 


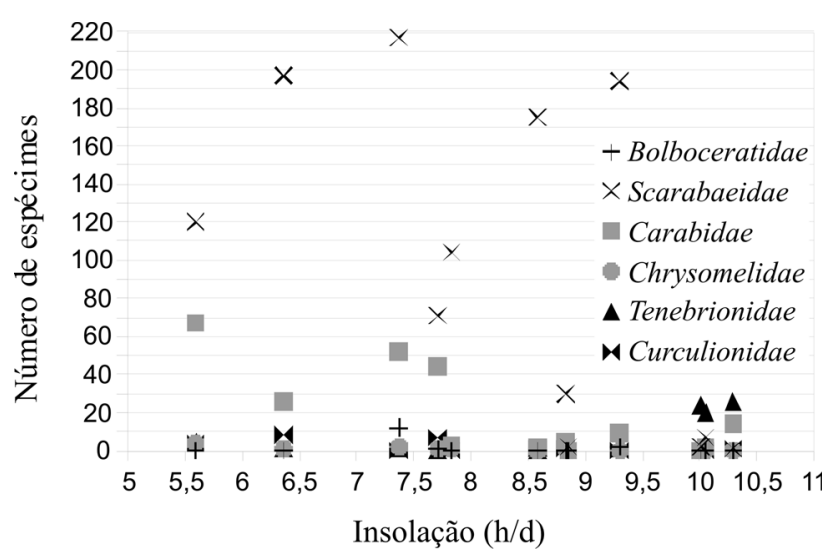

Figura 2 - Diagrama de dispersão de dados diários mensais de insolação vs. o registro de ocorrência mensal da flutuação populacional de famílias de besouros.

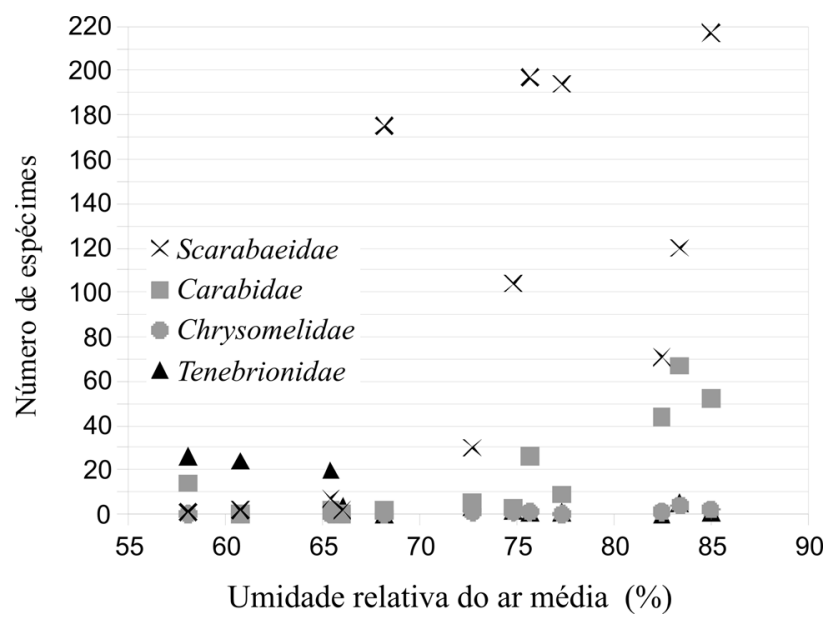

Figura 3 - Diagrama de dispersão de dados mensais de umidade relativa do ar compensada $v s$. o registro de ocorrência mensal da flutuação populacional de famílias de besouros.

que quando a temperatura ambiental é favorável, os insetos menores são beneficiados pela fácil troca de calor com o ambiente; tendo, também, atividade respiratória e circulatória mais eficientes, atividade metabólica mais intensa e maior capacidade de aproveitamento dos recursos alimentares. Gallo et al. (2002) descrevem que em geral para os insetos a temperatura ótima para o desenvolvimento mais rápido e para o maior número de descendentes está próxima de $25{ }^{\circ} \mathrm{C}$; e consideram que a faixa ótima para o desenvolvimento da maioria dos insetos se encontra entre $15 \mathrm{e}$ $38^{\circ} \mathrm{C}$. Em área de Mata de Cocal, houve associação nega-

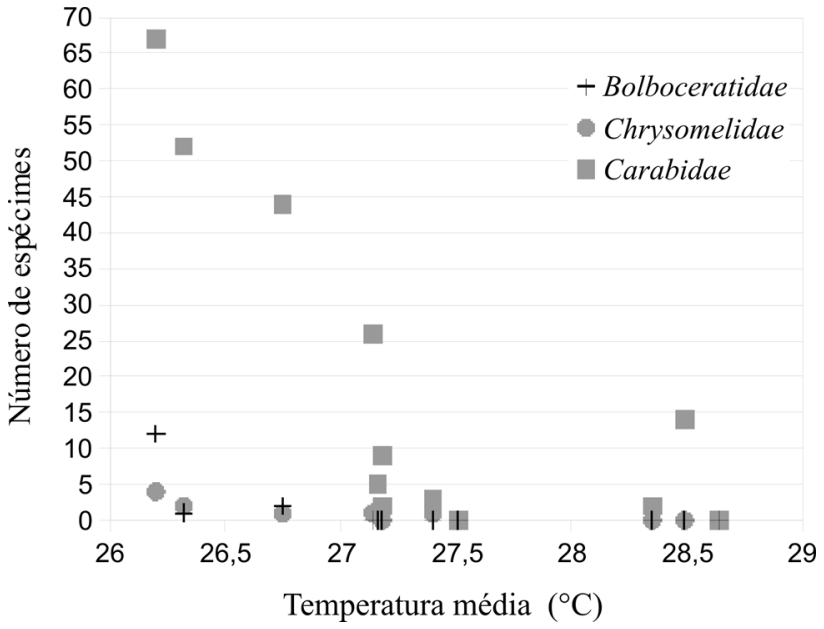

Figura 4 - Diagrama de dispersão de dados mensais de temperatura relativa média do ar compensada vs. o registro de ocorrência mensal da flutuação populacional de famílias de besouros.

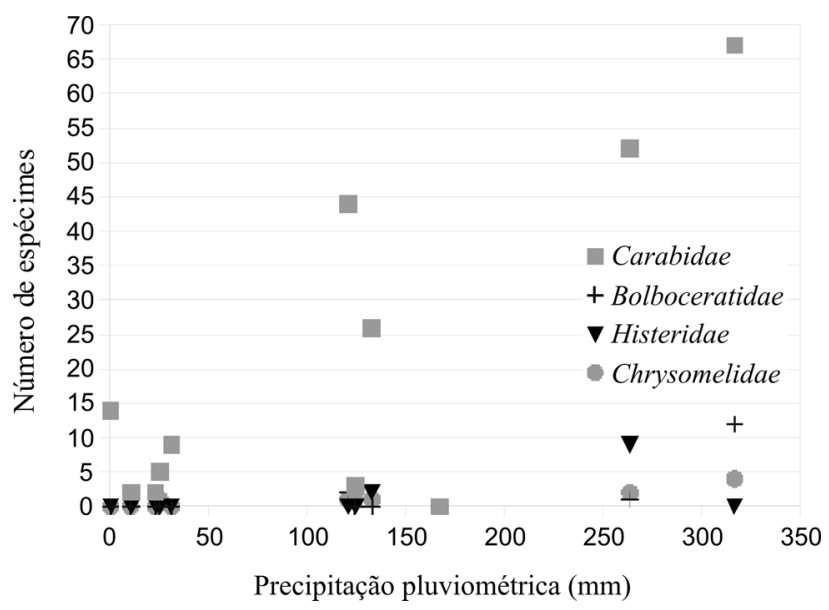

Figura 5 - Diagrama de dispersão de dados mensais de precipitação pluviométrica $v s$. o registro de ocorrência mensal da flutuação populacional de famílias de besouros.

tiva significativa $(-0,21 ; \mathrm{p}<0,0001)$ entre os dados mensais da temperatura média do ar compensada e o conjunto dos registros de ocorrência mensal da flutuação populacional das famílias de besouros já citadas. Entre as variáveis, a temperatura teve a menor associação.

Rodrigues (2004) considera que alguns insetos necessitam, como as plantas, de um determinado número de horas de sol para completar seu desenvolvimento; interferindo as horas na fertilidade e na longevidade. Basset

Tabela 4 - Correlação canônica entre os registros de ocorrência mensal da flutuação populacional de famílias de coleópteros e o conjunto dos dados mensais das variáveis meteorológicas (U).

\begin{tabular}{cccccccc}
\hline & Scarabaeidae & Carabidae & Tenebrionidae & Curculionidae & Bolboceratidae & Histeridae & Chrysomelidae \\
\hline $\mathrm{U}$ & $-0,22$ & $-0,22$ & 0,52 & $-0,13$ & 0,52 & 0,37 & $-0,74$ \\
\hline
\end{tabular}

$\mathrm{R}$ canônico = 0,9993; R2 canônico = 0,9985; $\chi 2=66,6204 ; \mathrm{GL}=28 ; \mathrm{p}$ - valor $<0,0001$. 
Tabela 5 - Correlação canônica entre os dados mensais das variáveis meteorológicas e o conjunto dos registros de ocorrência mensal da flutuação populacional de famílias de coleópteros (V).

\begin{tabular}{lcccc}
\hline & Insolação $\left(\mathrm{h} . \mathrm{d}^{-1}\right)$ & Umidade relativa do ar $(\%)$ & Precipitação (mm) & Temperatura média $\left({ }^{\circ} \mathrm{C}\right)$ \\
\hline $\mathrm{V}$ & 0,81 & $-0,75$ & 0,45 & $-0,21$ \\
\hline
\end{tabular}

$\mathrm{R}$ canônico $=0,9993 ; \mathrm{R} 2$ canônico $=0,9985 ; \chi 2=66,6204 ; \mathrm{GL}=28$; p-valor $<0,0001$.

(1992), citado por Gonçalves e Louzada (2005), considera que ao lado da umidade e da temperatura a insolação é determinante para a distribuição da riqueza faunística de insetos. Os dados mensais da média diária de insolação associaram-se positivamente e significativamente $(0,81$; $\mathrm{p}<0,0001)$ ao conjunto dos registros de ocorrência mensal de espécimes das famílias. Entre as variáveis, a insolação teve a maior associação.

Rodrigues (2004) aponta que a porção de água contida no corpo dos insetos varia entre 70 a $90 \%$ e que essa variação depende do tipo de alimento que consomem e do ambiente em que vivem. A umidade relativa do ar esta relacionada de forma direta com a exposição dos insetos ou seu resguarde, o baixo teor de umidade pode afetar a fisiologia, longevidade, desenvolvimento e oviposição dos insetos (Gullan e Cranston, 2007). Gallo et al. (2002) descrevem que a faixa favorável para a maioria dos insetos para maior velocidade de desenvolvimento, maior longevidade e maior fecundidade varia entre 40 a $80 \%$. Houve associação negativa significativa $(-0,75 ; \mathrm{p}<0,0001)$ entre os dados mensais da umidade relativa do ar compensada e o conjunto dos registros de ocorrência mensal da flutuação populacional das famílias.

A precipitação pluviométrica pode interferir também indiretamente nos insetos. Marinoni e Ganho (2003), em áreas com diferentes graus de antropização e de sucessão vegetal em Ponta Grossa - PR, consideram que a sazonalidade dos insetos é relacionada ao período chuvoso, pois há ocorrência de maior disponibilidade de recursos alimentares, o que proporciona um pico populacional elevado. Contudo, deve-se observar que o excesso hídrico pode ser prejudicial às plantas, porquanto lhes pode proporcionar estresse hídrico; e o habitat, solo, de alguns insetos pode ficar encharcado. Os dados mensais da precipitação pluviométrica associaram-se positivamente e significativamente $(0,45 ; p<0,0001)$ ao conjunto dos registros de ocorrência mensal da flutuação populacional das famílias.

Há estudos em que houve o maior registro de espécimes amostrados na estação chuvosa e há outros em que não houve diferença significativa entre a estação chuvosa e a estação seca. Por exemplo, em um fragmento de Mata Atlântica na Reserva Ecológica de Gurjaú - PE, Santos (2005) obteve $71,5 \%$ do total de espécimes amostrados na estação chuvosa (maio e julho de 2003) e 28,5\% do total de besouros amostrados na estação seca (outubro e novembro de 2003); enquanto, em fragmentos de floresta serrana de brejo de altitude no estado de Paraíba, Neves (2006) obteve na estação chuvosa de abril a julho de 2005, 53\% do total dos coleópteros amostrados e na estação seca de novembro de 2004 a fevereiro de 2005, 47\% do total de besouros amostrados.

\subsection{Nicho ecológico}

Os indivíduos das famílias identificadas ocupam posição funcional ou posição biológica dentro do ecossistema em que estão inseridos. Isso compreende o que os espécimes representam no quadro geral do ecossistema, pelo que eles fazem e como fazem.

\subsubsection{Família Scarabaeidae}

Os insetos da família Scarabaeidae são detritívoros, cuja alimentação se baseia em massa fecal de mamíferos, coprofagia; restos de animais mortos, necrofagia; e frutos em decomposição, saprofagia, (Halffter e Matthews, 1966). No ato de transportar e enterrar a maior parte dos excrementos que se utilizam, esses besouros acarretam a aceleração do processo de ciclagem dos nutrientes, tornando-o mais eficiente, aumentando a fertilidade do solo (Koller et al., 1997). Desta maneira, conforme Nichols et al. (2008) e Slade et al. (2011), os escarabeídeos são importantes nos ecossistemas por promoverem a remoção e reentrada de matéria orgânica no solo, auxiliando na reciclagem de nutrientes e melhorando a aeração do solo, e podendo ainda atuar na regulação de populações de outros artrópodes, inclusive pragas.

Rodrigues (1989) aponta que poucas espécies de besouros coprófagos sobrevivem em áreas com precipitação média anual inferior a $250 \mathrm{~mm}$ e que o número de indivíduos aumenta apenas no início das primeiras chuvas e com a elevação da temperatura do ar. Corroborando com esse entendimento, Campiglia (2002) e Paiva (2009) concluíram que, em pastagens, a flutuação populacional da comunidade de escarabeídeos e regida predominantemente pelas variáveis macroclimáticas da região e que a presença destes besouros é estacional e condicionada por parâmetros temporais, correlacionando negativamente à temperatura média do ar compensada e positivamente à umidade relativa média do ar compensada e à precipitação pluviométrica.

Significativamente, a família Scarabaeidae na Área de Mata Cocal associou-se positivamente à umidade relativa do ar compensada $(0,68 ; \mathrm{p}<0,05)$ e negativamente à insolação $(-0,55 ; \mathrm{p}<0,10)$. Em relação ao conjunto dos dados mensais das variáveis meteorológicas, houve associação negativa $(-0,22 ; \mathrm{p}<0,0001)$. O pico populacional ocorreu no mês de março com a identificação de 217 esca- 
rabeídeos. Registrou-se a presença de indivíduos da família Scarabaeidae todos os meses.

O pico populacional de determinada família ocorre quando o conjunto de mecanismos homeostáticos da natureza, em relação à própria família, tanto intrínsecos - internos - quanto extrínsecos - externos - é favorável ao seu desenvolvimento em um determinado habitat e em um determinado período de tempo. Os mecanismos intrínsecos dependem dos próprios integrantes da população, como é o caso da competição intraespecífica; enquanto os extrínsecos dependem da participação de alguma coisa fora da própria população, como a competição interespecífica, restrições de alimento e de espaço, os intemperismos, o parasitismo, o predatismo e as variações meteorológicas.

\subsubsection{Família Carabidae}

A maioria das espécies de carabídeos esconde-se durante o dia e sai à noite para se alimentar, uns poucos são atraídos pela luz conforme Borror e Delong (1969). Os mesmos autores citam que as espécies noturnas, durante o dia, permanecem escondidas em detritos foliares, debaixo de troncos e de pedras. Algumas espécies brilhantemente coloridas são diurnas (Booth et al., 1990). De acordo com Costa Lima (1952a), algumas espécies têm hábitos subterrâneos, outras são cavernícolas e algumas termitófilas ou mirmecófilas. Quanto ao hábito alimentar, conforme Paarmann et al. (2001), podem ser onívoros ou podem alimentar-se de sementes e de frutos caídos. Entretanto, de acordo com Costa Lima (1952a), a maioria das espécies - tanto as larvas quanto os adultos - é predadora de vários invertebrados - anelídeos; moluscos; larvas e adultos de insetos, principalmente lagartas de lepidópteros; entre outros artrópodes. Assim, representa um importante grupo utilizado no manejo de pragas e no controle biológico.

A família Carabidae associou-se positivamente à umidade relativa do ar compensada $(0,76 ; \mathrm{p}<0,01)$ e à precipitação pluviométrica $(0,80 ; \mathrm{p}<0,01)$; e negativamente à insolação $(-0,70 ; p<0,05)$ e à temperatura média do ar compensada $(-0,78 ; p<0,01)$. Ocorreu associação negativa $(-0,22 ; \mathrm{p}<0,0001)$ dessa família ao conjunto dos dados mensais das variáveis meteorológicas. Houve no mês de fevereiro com a identificação de 67 carabídeos o pico populacional dessa família.

\subsubsection{Família Tenebrionidae}

Marinoni et al. (2001) consideram que os tenebrionídeos são fundamentalmente detritívoros, alimentando-se de matéria de origem vegetal ou animal em decomposição e que algumas larvas vivem no solo alimentando-se de raízes e sementes, enquanto outras vivem em área de mata comendo fungos ou como predadoras facultativas. Os mesmos autores ainda classificam-nos em dois grupos: xilófilas, que ocorrem em madeira podre, associadas no câmbio e aos espaços subcorticais; e geófilas, que ocorrem no solo e no folhiço. Silva (2001) relata a ocorrência da espécie dessa família, Tribolium castaneum Herbst., 1797, em palmeira de coco babaçu.

A família Tenebrionidae associou-se negativamente à umidade relativa do ar compensada $(-0,78 ; \mathrm{p}<0,01)$ e positivamente à insolação $(0,73 ; p<0,01)$. Em relação ao conjunto dos dados mensais das variáveis meteorológicas, houve associação positiva $(0,52 ; \mathrm{p}<0,0001)$. O pico populacional dessa família ocorreu no mês de setembro com a identificação de 26 tenebrionídeos.

\subsubsection{Família Cerambycidae, Curculionidae e Scolytidae}

Os coleópteros da família Cerambycidae, da família Curculionidae e da família Scolytidae são os que mais ocorrem associados a espécies florestais nativas, e também exóticas, desempenhando papel importante na degradação da madeira como explica Gray (1972). Destacam-se pelo grande número de espécies e pelo alto grau de polifagia; podem ser xilófagos, micetófagos ou espermatófagos conforme Costa Lima (1952c). Silva (2001) relata a ocorrência de espécies dessas famílias em espécies florestais nativas, como da palmeira de coco babaçu. Esses insetos, de acordo com Hosking (1977), são comuns nas regiões tropicais e só atacam árvores vivas que apresentem alterações nas suas condições fisiológicas.

Nos curculionídeos, a base da alimentação é deficiente em vitaminas essenciais do grupo B e esteróis, cuja ausência é compensada por uma dieta rica em nitrogênio fornecida por fungos simbiontes que as sintetizam partindo de nutrientes absorvidos das galerias (Batra, 1963). Conforme Wood (1982), os espécimes destas famílias têm papel ecológico fundamental na formação de florestas, pois reciclam a biomassa vegetal e quando consomem os tecidos de seus hospedeiros, facilitam a entrada de organismos saprófitos que aceleram a deterioração desse material.

A família Curculionidae associou-se negativamente à insolação $(-0,60 ; p<0,05)$ e seu pico populacional ocorreu no mês de janeiro com a identificação de 8 curculionídeos. Em relação ao conjunto dos dados mensais das variáveis meteorológicas, essa família associou-se negativamente $(-0,22 ; \mathrm{p}<0,0001)$. O pico populacional da família Scolytidae ocorreu no mês de abril com 506 espécimes identificados.

\subsubsection{Família Histeridae}

Frequentemente, de acordo com Sampaio (2010), os histerídeos são encontrados onde há matéria orgânica em decomposição. Contudo, conforme Costa Lima (1952a), tanto os adultos, como as larvas, são predadores de outros insetos saprófagos ou xilófagos e que, também, há espécies de hábito saprófago ou micófago.

A família Histeridae associou-se positivamente à precipitação pluviométrica $(0,50 ; p<0,01)$ e ao conjunto dos dados mensais das variáveis meteorológicas $(0,37$; $\mathrm{p}<0,0001)$. Seu pico populacional ocorreu no mês de maio com a identificação de 9 histerídeos. 


\subsubsection{Família Bolboceratidae}

A maioria das espécies da família Bolboceratidae, como citam Scholtz e Browne (1995), escavam tocas para colocação de seus ovos. Conforme os mesmos autores, bolboceratídeos são tipicamente detritívoros, alimentando-se de matéria de origem vegetal ou animal em decomposição e seus adultos formam ninhos de serrapilheira (muitas vezes mofada); no entanto há espécies que colocam seus ovos dentro ou sobre a massa fecal, a qual posteriormente as larvas alimentam-se.

A família Bolboceratidae associou-se negativamente à insolação $(-0,61 ; \mathrm{p}<0,05)$ e à temperatura média do ar compensada $(-0,55 ; \mathrm{p}<0,10)$; e positivamente à precipitação pluviométrica $(0,69 ; \mathrm{p}<0,05)$. Houve associação positiva $(0,52 ; \mathrm{p}<0,0001)$ dessa família ao conjunto dos dados mensais das variáveis meteorológicas. $\mathrm{O}$ pico populacional desses coleópteros ocorreu no mês de fevereiro com a identificação de 12 bolboceratídeos.

\subsubsection{Família Chrysomelidae}

Os crisomelídeos, como citam Deloach et al. (2003), são majoritariamente herbívoros, se alimentam desde briófitas às gimnospermas e às angiospermas. De acordo com os mesmos autores, a maior parte é monófoga, no entanto há espécies polífagas e algumas são estudadas como agentes potenciais de controle biológico de ervas daninhas.

A família Chrysomelidae associou-se positivamente à umidade relativa do ar compensada $(0,72 ; \mathrm{p}<0,01)$ e à precipitação pluviométrica $(0,85 ; \mathrm{p}<0,01)$; e negativamente à insolação $(-0,81 ; \mathrm{p}<0,01)$ e à temperatura média do ar compensada $(-0,72 ; p<0,01)$. Em relação ao conjunto dos dados mensais das variáveis meteorológicas, houve associação negativa $(-0,74 ; p<0,0001)$. Entre as famílias, essa associação entre o conjunto das variáveis foi a maior. O pico populacional dessa família ocorreu no mês de abril com a identificação de 4 crisomelídeos.

\subsubsection{Família Staphylinidae}

Tanto os insetos adultos e as larvas de estafilinídeos apresentam uma gama variada de hábitos alimentares. De acordo com Sampaio (2010), ocorrem, em geral, em substância em decomposição (folhiço), principalmente esterco e carniça. O mesmo autor ainda afirma que a maioria das espécies são predadoras de outros insetos que vivem nestes materiais e que algumas espécies são parasitas, havendo algumas que se alimentam de fungos e musgos. Conforme Costa Lima (1952c), também, são encontrados frequentemente dentro da corola das flores, alimentando-se de pólen e que podem viver em comensalismo, mutualismo ou simbiose com formigas e térmitas. Em área de Mata de Cocal, registrou-se o pico populacional desses besouros no mês de abril com a identificação de 16 estafilinídeos.

\subsubsection{Familia Elateridae}

Conforme Costa Lima (1952b) muitos dos besouros da família Elateridae são quando larvas exclusivamente predadores ou detritívoros, se alimentando de madeira em decomposição. De acordo com o mesmo autor, há elaterídeos com hábitos terrícolas, roem raízes e a base do caule de plantas. Lima (2010) esclarece que no período de larva vivem em troncos de árvores e quando adultos buscam alimentos em novas áreas. No mês de dezembro, houve o pico populacional com o registro de 4 elaterídeos.

\subsubsection{Família Nitidulidae}

A família Nitidulidae demonstra adaptabilidade a ambientes antropizados, pois pode aparecer em alta densidade tanto em ambientes florestados como em áreas degradas (Medri e Lopes, 2001). Segundo Athié e Paula (2002), a maior parte são decompositores que se alimenta da seiva de árvores e do suco de frutas, principalmente fermentadas. Seu pico populacional ocorreu no mês de maio com a identificação de 9 nitidulídeos.

\subsubsection{Família Cantharidae}

Lawrence et al. (1999) consideram que os adultos da maioria das espécies de cantarídeos apresentam atividade diurna, sendo encontrados frequentemente sobre plantas. Em termos de dieta, os autores classificam-nos como predadores facultativos, uma vez que aliam ao consumo habitual de presas de pequena dimensão o consumo suplementar de matéria vegetal. Borror e Delong (1969) afirmam que as larvas são predadoras de outros insetos e as larvas, conforme Booth et al. (1990), vivem no solo, detritos foliares ou em madeira em decomposição.

\subsubsection{Família Meloidae}

Os adultos de Meloidae são desfolhadores e, assim, são considerados pragas de plantas cultivadas (ao contrário de suas larvas, que são predadoras), da mesma forma que algumas espécies de Chrysomelidae (Marinoni et al., 2003). As larvas da maioria dos meloídeos são consideradas benéficas, pois se alimentam de ovos de gafanhotos. Algumas vivem em colmeias de abelha durante o estágio larval alimentando-se dos ovos das abelhas e do alimento armazenado nas células com os ovos (Borror e Delong, 1969).

\subsubsection{Família Mordellidae}

Os adultos de Mordellidae, conforme Lawrence et al. (1999), encontram-se associados a flores e se alimentam de néctar e de pólen. De acordo com os mesmos autores, as suas larvas se desenvolvem no interior de madeira em decomposição, algumas espécies em talos de herbáceas, há também espécies que se alimentam de fungos da família Polyporaceae. São bastante ativos, quando perturbados imediatamente correm ou voam (Borror e Delong, 1969). 


\subsubsection{Família Bruchidae}

Costa Lima (1952c) sob o ponto de vista etológico divide os bruquídeos em dois grupos: os que põem os ovos nos frutos da planta hospedeira e as larvas se desenvolvem nas sementes desses frutos atacados; e os que põem os ovos diretamente sobre as sementes e as larvas que deles saem, nelas penetram e se desenvolvem, quando as sementes se acham, portanto, separadas do respectivo fruto. Silva (2001) relata a ocorrência da espécie dessa família, Pachymerus nucleorurn Fabricius, 1792, em palmeira de coco babaçu.

\subsubsection{Recomendação}

Todas as entidades físicas e biológicas de um determinado ecossistema formam um único sistema integrante unificado e complexo. Como visto, há vinculação profunda, direta e essencial dos besouros com os processos ecológicos do ecossistema em que estão inseridos. Dada essa importância, faz-se necessária a permanência deles no ambiente em que estão, para tanto deve haver a manutenção das condições meteorológicas relativas à insolação, à precipitação, à temperatura e à precipitação pluviométrica e a conservação da Mata de Cocal.

\section{Conclusão}

Constatou-se que o melhor período para realização de amostragens em Mata de Cocal para maximização amostral por meio de armadilhas de solo sem atrativos em estações é no período de dezembro a maio. Além de haver predominância das famílias Scarabaeidae, Scolytidae, Carabidae e Tenebrionidae.

Evidenciou-se que o registro da flutuação populacional das famílias Scarabaeidae, Carabidae, Tenebrionidae, Curculionidae, Bolboceratidae, Histeridae e Chrysomelidae é afetado ao longo do ano, porque as mesmas estão associadas em, pelo menos, a uma das variáveis insolação, temperatura média do ar compensada, umidade relativa média do ar compensada e precipitação pluviométrica. As famílias Carabidae e Chrysomelidae associaram-se significativamente a todas variáveis meteorológicas.

Confirmou-se a correlação canônica entre os conjuntos de variáveis registro de ocorrência mensal da flutuação populacional de famílias de besouros e os dados meteorológicos mensais, com magnitude de 0,99, Qui-Quadrado igual a 66,62, com 28 graus de liberdade e o correspondente $\mathrm{p}$-valor igual a $<0,0001$. Significativamente $(\mathrm{p}<0,0001)$, houve correlação canônica positiva entre os dados da insolação $(0,81)$ e da precipitação pluviométrica $(0,45)$, e negativa da umidade $(-0,75)$ e da temperatura $(-0,21)$ ao conjunto dos registros de ocorrência mensal da flutuação populacional de famílias de coleópteros. A maior associação entre o conjunto dos dados meteorológico foi da família Chrysomelidae $(-0,74 ; \mathrm{p}<0,0001)$.
Este estudo é baseado ao nível de família. Então, para estudos futuros deve-se averiguar se há variações entre a flutuação populacional das espécies de besouros dentro de cada família decorrentes das associações com as variáveis meteorológicas. Deste modo, o presente trabalho que mostra que a flutuação populacional de determinadas famílias de besouros, precipuamente da família Chrysomelidae, é estacional e condicionada por parâmetros meteorológicos, principalmente insolação e umidade relativa do ar, se torna importante como parâmetro para uma primeira descrição para posteriores refinamentos taxonômicos e inflexões mais aprofundadas.

\section{Agradecimentos}

Ao CNPq pela bolsa de iniciação científica concedida e ao engenheiro agrônomo Carlos Aydano Virgínio Frazão pelo auxílio na coleta, na triagem e na classificação dos insetos.

\section{References}

ANDRADE JÚNIOR, A.S.; BASTOS, E.A.; BARROS, A.H.C.; SILVA, C.O.; GOMES, A.A.N. Classificação climática e regionalização do semiárido do Estado do Piauí sob cenários pluviométricos distintos. Revista Ciência Agronômica, v. 36, n. 2, p. 143-151, 2005.

ATHIÉ, I.; PAULA, D.C.de. Insetos de grãos armazenados: aspectos biológicos e identificação. 2.ed. São Paulo: Varela, 2002.

AYRES, M.; AYRES JR., M.; AYRES, D.L.; DOS SANTOS, A.S. BioEstat: aplicações estatísticas nas áreas das ciências biológicas e médicas. Belém: Publicações Avulsas Mamirauá, 2007.

BASSET, Y. Host specificity of arboreal and free-living insect herbivores in rain forests. In: Biological Journal of the Linnean Society, n. 47, p. 115-133, 1992.

BASTOS, E.A.; ANDRADE JÚNIOR, A.S; MEDEIROS, R.M. Boletim agrometeorológico de 2010 para o município de Teresina, PI. Teresina: Embrapa Meio Norte série documentos - 210, 2011.

BATRA, L.R. Ecology of ambrosia fungiand their dissemination by beetles. Transactions of the Kansas Academy of Science, Lawrence, v. 66, n. 2, p. 213-36, 1963.

BOOTH, R.G.; COX, M.L.; MADGE, R.B. IIE guides to insects of importance to man: 3. Coleoptera. London: International Institute of Entomology / The Natural History Museum, 1990. 384p.

BORROR, D.J.; DELONG, D.M. Introdução ao estudo dos insetos. São Paulo: E. Blücher, 1969. 653p

BRANCO, R.T.P.C. Entomofauna associada à cultura da cana-de-açúcar no município de União - Piauí - Brasil. 2008. Dissertação (Mestrado em Agronomia: Produção vegetal), Universidade Federal do Piaú. Teresina 92f.

BROWER, J.E.; ZAR, J.H. Field and Laboratory Methods for General Ecology. 2. ed., Iowa: Wm. C. Brown Publishers, 1984.

BROWNE, D.J.; SCHOLTZ, C.H. Phylogeny of the families of the Scarabaeiodea (Coleoptera) based on characters of the 
hindwing articulation, hindwing base and wing venation. Systematic Entomology. n. 21: p. 145-173, 1995.

CAMPIGLIA, M. A influência de sistemas silvipastoris sobre a dinâmica populacional de besouros coprófagos. 2002. Dissertação (Mestrado em Agroecossistemas), Universidade Federal de Santa Catarina, Florianópolis, $127 \mathrm{f}$

COSTA LIMA, A. Insetos do Brasil. Tomo 7. Coleópteros. Rio de Janeiro: Série didática da Escola Nacional de Agricultura, 1952a.

COSTA LIMA, A. Insetos do Brasil. Tomo 8. Coleópteros. Rio de Janeiro: Série didática da Escola Nacional de Agricultura, $1952 b$.

COSTA LIMA, A. Insetos do Brasil. Tomo 9. Coleópteros. Rio de Janeiro: Série didática da Escola Nacional de Agricultura, 1952c.

COSTA, C. Coleoptera. In: JOLY, C.A.; BICUDO, C.E.M. (Org.). Biodiversidade do Estado de São Paulo, Brasil: síntese do conhecimento ao final do século XX. Invertebrados terrestres. São Paulo: Museu de Zoologia da Universidade de São Paulo, 1999.

COSTA, E.M.; ARAÚJO, E.L.; LOPES da SILVA, F.E.; NOGUEIRA, C.H.F.; SILVA, P.A.F. Diversidade de coleópteros em área cultivada com melancia no semiárido do rio grande do norte. Revista Agro@mbiente On-line, v. 8, n. 2, p. 293-297, mai.-ago. 2014.

DELOACH, C.J.; LEWIS, P.A.; HERR, J.C.; CARRUTHERS, R.I.; TRACY, J.L.; JOHNSON, J. Host specificity of the leaf beetle, Diorhabda elongata deserticola (Coleoptera: Chrysomelidae) from Asia, a biological control agent for saltcedars (Tamarix: Tamaricaceae) in the Western United States. Biological Control, v. 27, n. 2, p. 117-147, 2003.

DOYEN, J.T.; DALY, H.V.; PURCELL, A.H. Introduction to Insect Biology and Diversity. Oxford: Oxford University Press, 1998.

EMBRAPA. Sistema Brasileiro de Classificação de Solos. Rio de Janeiro: Embrapa Solos, 2006. 306p.: il. 2ed.

FARIAS, R.R.S.; CASTRO, A.A.J.F. Fitossociologia de trechos da vegetação do Complexo Campo Maior, PI, Brasil. Acta. Bot. Bras., v. 18, n. 4. p. 949-963, 2004.

GALLO, D.; NAKANO, O.; SILVEIRA NETO, S.; CARVALHO, R.P.L.; BATISTA, G.C.; BERTI FILHO, E.; PARRA, J.R.P.; ZUCCHI, R.A.; ALVES, S.B.; VENDRAMIM, J.D.; MARCHINI, L.C.; LOPES, S.R.S.; OMOTO, C. Entomologia Agrícola. Piracicaba: FEALQ, 2002.

GONCALVES, T.T.; LOUZADA, J.N.C. Estratificação vertical de coleópteros carpófilos (Insecta: Coleoptera) em fragmentos florestais do sul do Estado de Minas Gerais, Brasil. Ecol. austral, Córdoba, v. 15, n. 1, jun. 2005.

GRAY, B. Economic tropical forest entomology. Rev. Entomology, Stanford, v. 17, p. 313- 354, 1972.

GULLAN, P.J.; CRASTON, P.S. Os Insetos: Um Resumo de Entomologia. Traduzido por Sonia Maria Marques Hoenen. São Paulo: Roca, 2007.

HALFFTER, G.; MATTHEWS, E.G. The natural history of dung beetles of the subfamily Scarabaeinae (Coleoptera: Scarabaeidae). Folia Entomológica Mexicana, v. 12, n. 14, p. 1-312, 1966.

HOSKING, G.P. Xyleborus saxeseni, its life-history and flight behaviour in New Zealand. New Zealand Journal of Forestry Science, Rotoura, v. 3, n.1, p. 37-53, 1977.
INSTITUTO BRASILEIRO DE GEOGRAFIA E ESTATÍSTICA (IBGE). Manual técnico da Vegetação Brasileira. Série Manuais Técnicos em Geociências. n. 1. Rio de Janeiro: Ed. IBGE. 91p, 1992.

KOLLER, W.W.; GOMES, A.; FLECHTMANN, C.A.H.; RODRIGUES, S.R.; BIANCHIN, I.; HONER, M.R. Ocorrência e sazonalidade de besouros copro/necrófagos (Coleoptera; Scarabaeidae), em massas fecais de bovinos, na região de Cerrados doMato Grosso do Sul. Campo Grande: EMBRAPA CNPGC, 1997.

LAWRENCE, J.F.; HASTINGS, A.M.; DALLWITZ, M.J.; PAINE, T.A.; ZURCHER, E.J. Beetles of the World. A Key and Information System, for Families and Subfamilies. CD-ROM. CSIRO Publishing, Caberra: 1999.

LIMA, R.L.; ANDREAZZE, R.; ANDRADE, H.T.A.; PINHEIRO, M.P.G. Riqueza de famílias e hábitos alimentares em Coleoptera capturados na fazenda da EMPARN - Jiqui, Parnamirim/RN. Entomobrasilis, v. 3, n. 1, p. 11-15, 2010.

MARINONI, R.C. Os grupos tróficos em Coleoptera. Rev. Bras. Zool., Curitiba, v. 18, n. 1, p. 205-224, mar. 2001.

MARINONI, R.C.; GANHO, N.G. Fauna de Coleoptera no Parque Estadual de Vila Velha, Ponta Grossa, Paraná, Brasil: abundância e riqueza das famílias capturadas através de armadilhas malaise. Rev. Bras. Zoologia, Curitiba, v. 20, n. 4, p. 737-744, dec.2003.

MARINONI, R.C.; GANHO, G.; MONNÉ, M.L.; MERMUDES, J.R.M. Hábitos Alimentares em Coleóptera (Insecta). Ribeirão Preto: Holos Editora Ltda., 2001.

MEDRI, I.M.; LOPES, J. Coleopterofauna em floresta e pastagem no norte do Paraná, Brasil, coletada com armadilha de solo. Rev. Bras. Zool., Curitiba, v. 18, supl. 1, p. 125-133, 2001.

NEVES, C. M. L. Análise da vegetação e da entomofauna de coleópteros ocorrentes em fragmentos de floresta serrana de brejo de altitude no estado da Paraíba. Dissertação (Mestrado Agronomia: Ecologia vegetal e Meio Ambiente), Universidade Federal da Paraíba. Areia. 133f.

NICHOLS, E.; SPECTOR, S.; LOUZADA, J.; LARSEN, T.; AMEZQUITA, S.; FAVILA, M.E. Ecological functions and ecosystem services provided by Scarabaeinae dung beetles. Biological Conservation, v. 141, n. 6, p. 1461-1474, 2008.

PAARMANN, W.; ADIS, J.; STORK, N.; GUTZMANN, B.; STUMPE, P.; STARITZ, B.; BOLTE, H.; KÜPPERS, S.; HOLZKAMP, K.; NIERS, C.; FONSECA, C.R.V.da. 2001. The structure of ground beetle assemblages (Coleoptera: Carabidae) at fig fruit falls (Moraceae) in terra firme rain forest near Manaus (Brazil). Journal of Tropical Ecology. v. 17, n. 4, jul., p. 549-561, 2001.

PAIVA, D.R. Escarabeíneos (coleoptera: scarabaeidae) associados a diferentes sistemas de manejo de pastagens no município de Teresina-PI. 2009. Dissertação (Mestrado em Agronomia: Produção vegetal), Universidade Federal do Piauí. Teresina. 56f.

RODRIGUES, L.R.A. Os besouros coprófagos em pastagens. Anais do Simpósio sobre Ecossistema de Pastagens. Jaboticabal, p. 97-133, 1989.

RODRIGUES, W.C. Fatores que influenciam no Desenvolvimento dos insetos. Info Insetos, v. 1, n. 4. 2004.

SAMPAIO, J.A. 2010 Levantamento e grupos tróficos de coleópteros cursores de solo em Sergipe: importância dos coleópteros como indicadores de processos de recuperação 
florestal. Dissertação (Mestrado em Agroecossistemas), Universidade Federal de Sergipe, São Cristóvão. $38 \mathrm{f}$.

SANTOS, S.R.de.A. 2005. Diversidade de Coleoptera em um fragmento de Mata Atlântica da reserva Ecológica Gurjaú, Cabo de Santo Agostinho - PE. 2005. Dissertação (Mestrado em Ciências Biológicas: Biologia Animal), Universidade Federal de Pernambuco. Recife. 37f.

SANTOS-FILHO, F.S.; ALMEIDA JR., E.B.; SOARES, C.J.R.S.; ZICKEL, C.S. Fisionomias das restingas do Delta do Parnaíba, Nordeste, Brasil. Revta. Bras. Geog. Física, v. 3, n. 3, p. 218-227, 2010.

SILVA. P.H.S.da. Insetos associados ao babaçu (Orbjgnye spp) no Estado do Piauí. Teresina: Embrapa Meio Norte. 2001.

SLADE, E.M.; MANN, D.J.; LEWIS, O.T. Biodiversity and ecosystem function of tropical forest dung beetles under con- trasting logging regimes. Biological Conservation, v. 144, n. 1, p. 166-174, 2011.

THORNTHWAITE, C.W.; MATHER, J.R. The water balance. Publications in Climatology - Drexel Institute of Technology. New Jersey, v. 8, n. 1, p. 1-86, 1955.

TRIPLEHORN, C.A.; JONHSON, N.F. Borror and delong's introdution to the study of insects, 7ed. Thomson Brooks/Cole, 2005.

WOOD, S.L. The bark and ambrosia beetles of north and central America (Coleoptera: Scolytidae) a taxonomic monograph. Great Basin Naturalist Memoirs. Utah: Brigham Young University, 1982.

This is an Open Access article distributed under the terms of the Creative Commons Attribution Non-Commercial License which permits unrestricted non-commercial use, distribution, and reproduction in any medium provided the original work is properly cited. 